\title{
AVALIAÇÃo FÍSICO-QUÍMICA E MICROBIOLÓGICA DE SALAME TIPO ITALIANO
}

\author{
B. R. THOMÉ ${ }^{1}$, M. G. PEREIRA ${ }^{2}$, F. A. B. TOGNON ${ }^{3}$, M. D. MASSAROLLO ${ }^{4}$, F. A. C. \\ FOLLADOR $^{5}$
}

${ }^{1}$ Universidade do Estado de Santa Catarina - Departamento de Engenharia de Alimentos

${ }^{2}$ Universidade do Estado de Santa Catarina - Departamento de Engenharia de Alimentos

${ }^{3}$ Universidade Estadual do Oeste do Paraná, Programa de Pós Graduação Stricto Sensu em Gestão e Desenvolvimento Regional - Nivel de Mestrado. Bolsista Capes

${ }^{4}$ Universidade Estadual do Oeste do Paraná, Programa de Pós Graduação Stricto Sensu em Gestão e

Desenvolvimento Regional - Nivel de Mestrado. Bolsista Capes/Fundação Araucária

${ }^{5}$ Universidade Estadual do Oeste do Paraná, Programa de Pós Graduação Stricto Sensu em Gestão e Desenvolvimento Regional - Nivel de Mestrado

E-mail para contato: brunitta7@hotmail.com

RESUMO - O Salame Tipo Italiano é um dos produtos cárneos industrializados mais consumido e apreciado no Brasil, por sua conveniência e também por suas características sensoriais. A qualidade de salames é avaliada em função dos teores máximos de umidade, proteína, gordura, carboidratos e atividade de água. Quanto ao aspecto microbiológico, este produto é considerado em condições seguras para o consumo quando Salmonella sp., Staphylococcus aureus e Coliformes a $45^{\circ} \mathrm{C}$ estão de acordo com o preconizado pela legislação. Este trabalho teve como objetivo avaliar a qualidade de Salames Tipo Italiano comercializados no município de Francisco Beltrão (PR). Foram avaliadas 5 marcas distintas de Salames Tipo Italiano, através de análises físico-químicas de umidade, proteína, gordura, carboidratos e atividade de água e microbiológicas de Salmonella sp. Staphylococcus aureus e Coliformes a $45^{\circ} \mathrm{C}$. Das marcas analisadas, três apresentaram teores de umidade acima do permitido pela legislação. Para os demais parâmetros físicoquímicos, todas as marcas apresentaram resultados em conformidade com o Regulamento Técnico. Nenhuma amostra apresentou contaminação por Salmonella sp. e Staphylococcus aureus, entretanto, duas marcas apresentaram contaminação por Coliformes Totais.

\section{INTRODUÇÃO}

O salame é um dos produtos cárneos brasileiros mais atrativos e tradicionais e se evidencia por possuir sabor marcante e oferecer praticidade a quem o consome. Para Andreoli (2009), o tipo Italiano é o salame com maior produção e consumo no país. É aceito em grande parte do Brasil, principalmente na região sul, onde, de acordo com Terra et al. (2004), teve sua fabricação originada com a imigração italiana. 


\section{9 a 22 de outubro de 2014 \\ Florianópolis/SC}

A Instrução Normativa $n^{\circ}$ 22, de 31 de julho de 2000, do Ministério da Agricultura, Pecuária e Abastecimento Brasil (2000), define as características de identidade e qualidade de oito tipos de salames. Desta forma, denominando Salame Tipo Italiano o produto embutido, industrializado a partir de carne suína, como também pode ser produzido da mistura de carne suína e bovina, adicionado de toucinho e ingredientes, fermentado, curado, podendo passar por processo de defumação e finalmente é dessecado, sendo o tempo definido pelo processo de fabricação. A presença de mofo é decorrência do processo tecnológico de fabricação.

A qualidade de salames é avaliada em função dos teores de umidade, gordura, carboidratos totais, atividade de água e proteína. No caso de Salame Tipo Italiano, esses valores são, respectivamente, máximos de 35\%,32\%, 4\% e 0,90 e mínimo de 25\% (Brasil, 2000). Quanto os padrões microbiológicos para o Salame Tipo Italiano estão definidos na $\mathrm{RDC} \mathrm{n}^{\circ} 12$, de 2 de janeiro de 2001, da Agência Nacional de Vigilância Sanitária, e são: ausência de Salmonella sp. em $25 \mathrm{~g}$ do alimento, tolerância de $5 \times 10^{3} \mathrm{UFC} / \mathrm{g}$ para Staphylococcus aureus e a tolerância de $10^{3} \mathrm{UFC} / \mathrm{g}$ para Coliformes a $45^{\circ} \mathrm{C}$ (Brasil, 2001).

Os derivados cárneos estão expostos a diversas modificações como alterações físicas, químicas e microbiológicas. As duas primeiras se referem às alterações de decomposição de proteínas e lipídeos, devido à ação de agentes naturais e outras substâncias. Já, as alterações microbiológicas decorrem da ausência de condições higiênico-sanitárias, seja do local do processamento ou dos manipuladores, oferecendo condições para que se desenvolvam bactérias deterioradoras e patogênicas (IAL, 2008). Para Garcia et al. (2000), a variação das propriedades físicas e químicas do Salame Tipo Italiano são interdependentes durante o processamento e que assim, qualquer mudança proposta terá influência sobre o produto final.

Conforme Maciel et al. (2003), falhas no processo podem permitir a proliferação de patógenos como Staphylococcus e Salmonella os quais são responsáveis por surtos de doenças transmitidas por alimentos envolvendo embutidos fermentados. Para Kuchenbecker (2009), Staphylococcus aureus é um microrganismo anaeróbio facultativo, gram-positivo e não esporulado, de ocorrência frequente principalmente na presença de matéria orgânica. É uma bactéria patogênica e uma das maiores causadoras de gastroenterite ocasionada por alimentos contaminados.

De acordo com Forsythe (2002), a Salmonella pertence ao gênero da família Enterobacteriaceae, são bastonetes gram-negativos, aeróbicos facultativos e não formam esporos. Por não formarem esporos são relativamente sensíveis a temperaturas altas podendo assim, serem eliminados a $60^{\circ} \mathrm{C}$, por tempo médio de 20 minutos, nesta temperatura. A presença de coliformes no alimento indica a contaminação durante o processo de fabricação. Os coliformes são bactérias gram-negativas, anaeróbias facultativas e usualmente utilizadas para avaliar a segurança e higiene alimentar.

Este trabalho teve como objetivo avaliar a qualidade de Salames Tipo Italiano comercializados no município de Francisco Beltrão (PR), através da determinação das 
características físico-químicas e microbiológicas e comparar os resultados com os Regulamentos Técnicos específicos.

\section{MATERIAL E MÉTODOS}

Foram adquiridas três amostras de lotes diferentes de cinco marcas distintas de Salame Tipo Italiano comercializadas em diferentes estabelecimentos comerciais do município de Francisco Beltrão (PR), sendo uma amostra a cada quinze dias, entre março e abril de 2012, totalizando 15 amostras. As marcas foram identificadas como A, B, C, D, E as quais possuíam, a cada aquisição, datas de fabricação próxima. As marcas A, B e E são provenientes de abatedouros com inspeção federal (SIF) e as marcas C e D são de abatedouros com inspeção municipal (SIM).

As análises físico-químicas de umidade, proteína, gordura e carboidratos foram realizadas de acordo com a metodologia preconizada na Instrução Normativa no 20, de 21 de julho de 1999, do Ministério da Agricultura, Pecuária e Abastecimentos, em duplicata. Não consta nesta Instrução Normativa a metodologia para a análise de Atividade de Água, então esta foi realizada conforme a instrução do fabricante do equipamento, em duplicata.

As análises microbiológicas de contagem de Staphylococcus aureus, Coliformes Termotolerantes e a pesquisa de Salmonella spp foram realizadas de acordo com as metodologias AOAC Official Method 2003.07, AOAC Official Method 998.08 e 991.14 e Método AOAC Official Method 996.08 respectivamente, preconizados pelo Ministério da Agricultura, Pecuária e Abastecimento (BRASIL, 2003). Todas as análises microbiológicas foram realizadas em duplicata.

Os resultados físico-químicos foram avaliados através do teste de Tukey ao nível de 5\% de significância. A avaliação estatística dos resultados foi realizada com auxílio do software Statistica $^{\circledR}$ versão 7.0 (STATSOFT, Inc. 2004).

\section{RESULTADOS E DISCUSSÃO}

De acordo com o Regulamento Técnico de Identidade e Qualidade, o Salame Tipo Italiano deve apresentar as seguintes características físico-químicas: Atividade de Água (máx.) de 0,90; Umidade (máx.) de 35\%; Gordura (máx.) de 32\%; Proteína (mín.) de 25\% e Carboidratos Totais (máx.) de 4,0\% (Brasil, 2000). Já para avaliação da qualidade microbiológica a Resolução $\mathrm{n}^{\circ}$ 12, de 2 de janeiro de 2001, da Agência Nacional de Vigilância Sanitária - ANVISA estabelece como padrão para salame a ausência de Salmonella sp. em $25 \mathrm{~g}$ do alimento, a tolerância de $5 \times 10^{3} \mathrm{UFC} / \mathrm{g}$ para Staphylococcus aureus e a tolerância de $10^{3} \mathrm{UFC} / \mathrm{g}$ de produto para Coliformes a $45^{\circ} \mathrm{C}$ (Brasil, 2001),.

$\mathrm{Na}$ Tabela 1, estão demonstrados os resultados das análises físico-químicas dos Salames Tipo Italiano, comercializados no município de Francisco Beltrão (PR).

Tabela 1 - Médias das análises físico-químicas \pm desvio padrão 


\begin{tabular}{l|l|l|l|l|l}
\hline Marcas & Gordura (\%) & Umidade (\%) & CT (\%) (*) & Aw (**) & Proteína (\%) \\
\hline A & $31,59^{\mathrm{a}} \pm 0,50$ & $31,43^{\mathrm{a}} \pm 0,22$ & $3,76^{\mathrm{a}} \pm 0,06$ & $0,77^{\mathrm{a}} \pm 0,02$ & $29,43^{\mathrm{a}} \pm 0,10$ \\
\hline B & $26,44^{\mathrm{b}} \pm 0,05$ & $29,92^{\mathrm{b}} \pm 0,12$ & $2,04^{\mathrm{b}} \pm 0,10$ & $0,75^{\mathrm{a}} \pm 0,02$ & $38,22^{\mathrm{b}} \pm 1,20$ \\
\hline C & $22,01^{\mathrm{c}} \pm 0,17$ & $38,97^{\mathrm{ce}} \pm 4,43$ & $2,2^{\mathrm{c}} \pm 0,05$ & $0,86^{\mathrm{bc}} \pm 0,06$ & $34,7^{\mathrm{c}} \pm 0,17$ \\
\hline $\mathrm{D}$ & $29,16^{\mathrm{d}} \pm 0,09$ & $38,04^{\mathrm{c}} \pm 0,09$ & $2,15^{\mathrm{c}} \pm 0,05$ & $0,86^{\mathrm{bd}} \pm 0,04$ & $29,36^{\mathrm{a}} \pm 0,15$ \\
\hline E & $26,66^{\mathrm{e}} \pm 0,19$ & $37,05^{\mathrm{e}} \pm 0,22$ & $1,74^{\mathrm{e}} \pm 0,14$ & $0,85^{\mathrm{cd}} \pm 0,01$ & $33,84^{\mathrm{d}} \pm 0,23$ \\
\hline
\end{tabular}

Médias na mesma coluna, seguidas de letras iguais, não diferem significativamente. entre si, ao nível de significância de $5 \%$.

(*) $\mathrm{CT}=$ Carboidratos Totais

(**) Aw = Atividade de Água

Todas as amostras analisadas estavam em conformidade com a legislação brasileira nos parâmetros físico-químicos de proteína, gordura e carboidratos totais.

Os teores de proteína variaram de $29,36 \%$ a 38,22\% encontrando-se de acordo com os padrões citados no regulamento técnico para Salame Tipo Italiano. As marcas A e D não apresentaram diferença significativa $(\mathrm{p}>0,05)$ entre si. A proteína possui elevado valor biológico e as proteínas miofibrilares, as quais são extraídas pelo cloreto de sódio, contribuem com a liga proporcionando maior capacidade de retenção de água e emulsificação da gordura (Pardi et al., 2001).

Os resultados obtidos para carboidratos totais demonstraram que a marca $\mathrm{E}$ apresentou o menor teor de carboidrato $(\mathrm{p}<0,05)$ quando comparada com as demais marcas. Os teores de carboidratos totais variaram de $1,74 \%$ a $3,76 \%$ estando assim, dentro dos padrões propostos pela legislação. As marcas C e D não apresentaram entre si diferença significativa ( $>0,05)$. Os carboidratos existentes na formulação cárnea são de grande importância já que as bactérias ácidoláticas utilizam-se dele para produzir ácido lático. Este, por sua vez, é responsável pela segurança e qualidade dos produtos cárneos fermentados, pois possui efeito protetor contra diversos microorganismos indesejáveis como o Staphylococcus aureus (Terra, 2005).

$\mathrm{Na}$ análise de atividade de água não houve diferença significativa $(\mathrm{p}<0,05)$ entre as marcas A e B e entre as marcas C, D e E. Os resultados das medições de atividade de água variaram de 0,75 a 0,86 , sendo que a marca B apresentou o menor valor para esta análise. Cavalheiro et al. (2010), avaliaram as características de embutido curado fermentado adicionado de carne de avestruz associada à carne de suíno e encontraram valores de atividade de água de 0,85 e 0,89 , portanto próximos aos encontrados nesse trabalho. A marca $\mathrm{C}$ apresentou, em um dos lotes observados, valor de atividade de água de 0,91 estando acima dos estabelecidos pela legislação, condizendo-se com os altos índices de umidade observados para esta mesma marca. Isso responde a correlação entre umidade e atividade de água, visto que, quanto maior a umidade maior a água livre, tornando o meio favorável ao crescimento microbiano.

Os teores de gordura variaram de 22,01 a $31,59 \%$, sendo que houve diferença significativa $(\mathrm{p}<0,05)$ entre todas as marcas analisadas. Em relação à umidade, constatou-se que três marcas 
(C, D, E) dos salames avaliados apresentaram valores superiores aos fixados pela legislação. As marcas $C$ e $D$ assim como $C$ e $E$ não apresentaram diferença significativa $(p>0,05)$. Os teores de umidade variaram de 29,92 a $38,97 \%$ e a marca $C$ foi a que obteve percentual superior aos demais $(\mathrm{p}<0,05)$. Esta mesma marca apresentou baixo teor de gordura $(\mathrm{p}<0,05)$ quando comparada com as outras marcas, porém está de acordo com os valores fixados na legislação. Estes resultados assemelham-se aos encontrados por Stolberg et al. (2006), em Salames Tipo Coloniais que, em 12 amostras avaliadas 83,3\% obtiveram valores de umidade acima dos indicados na legislação apresentando também, baixos teores de gordura. Caccioppoli et al. (2006), analisaram aminas bioativas e as características físico-químicas de sete marcas Salames Tipo Italiano em Belo Horizonte, MG, e, de um total de 42 amostras, apenas $29 \%$ atenderam aos valores fixados pela legislação para umidade.

Visto que o tempo de secagem de salame é definido pelos próprios fabricantes e que este ainda é um grande desafio encontrado, os salames chegam ao consumidor com diferentes percentuais de umidade mesmo com datas de fabricação próximas podendo assim, explicar estes valores acima do proposto pela legislação.

Segundo Terra et al. (2004), a umidade é um fator que deve ser controlado para que as características organolépticas do produto se mantenham por maior tempo e para evitar o desenvolvimento de micro-organismos deteriorantes. Estes dados corroboram com o que foi observado em duas marcas (C e D) que apresentaram percentuais elevados de umidade apresentaram também contaminação por coliformes a $45^{\circ} \mathrm{C}$ (Tabela 2), marcas estas provenientes de abatedouros com inspeção municipal. A presença de coliforme no alimento sugere a contaminação que pode ser desde o processo como utensílios e manipuladores. Resultados similares foram encontrados por Senter et al. (2010), quando avaliaram 30 amostras de salames artesanais dos quais $43,33 \%$ estavam contaminadas por coliformes fecais, com níveis acima dos permitidos pela legislação, tornado os produtos impróprios ao consumo. Em estudo realizado por Zocche et al. (2011), foram avaliadas 34 amostras de salames industriais na cidade de Palotina, $\mathrm{PR}$, onde foi detectado contagem de coliformes termotolerantes acima dos níveis aceitáveis pela RDC $\mathrm{n}^{0} 12$, enquadrando estas amostras como produto em condições higiênico-sanitárias insatisfatórias (Brasil, 2001).

Para as análises microbiológicas de Salmonella sp. 100\% das amostras indicaram ausência desta bactéria, que quando presente em alimentos é uma fonte potencializadora de surtos alimentares em humanos como as salmoneloses, que provocam diarréia, náusea, dor abdominal, febre branda e algumas vezes vômito e dor de cabeça. As análises de Staphylococcus aureus também foram satisfatórias para todas as cinco marcas, pois nenhuma apresentou contaminação por este microrganismo patogênico também responsável por surtos de intoxicações alimentares. 
Tabela 2 - Valores dos parâmetros microbiológicos das cinco marcas de Salames Tipo Italiano comercializados no município de Francisco Beltrão

\begin{tabular}{|c|c|c|c|c|}
\hline Marca & Coleta & $\begin{array}{c}\text { Coliformes a } 45^{\circ} \mathrm{C} \\
(\mathrm{UFC} / \mathrm{g})\end{array}$ & $\begin{array}{l}\text { Salmonella spp } \\
\quad(\mathrm{em} 25 \mathrm{~g})\end{array}$ & $\begin{array}{c}\text { Staphylococcus aureus } \\
(\mathrm{UFC} / \mathrm{g})\end{array}$ \\
\hline A & $1^{\mathrm{a}}$ & $<1,0 \times 10$ & Ausência & $<1,0 \times 10$ \\
\hline A & $2^{a}$ & $<1,0 \times 10$ & Ausência & $<1,0 \times 10$ \\
\hline A & $3^{\mathrm{a}}$ & $<1,0 \times 10$ & Ausência & $<1,0 \times 10$ \\
\hline $\mathrm{B}$ & $1^{\mathrm{a}}$ & $<1,0 \times 10$ & Ausência & $<1,0 \times 10$ \\
\hline $\mathrm{B}$ & $2^{a}$ & $<1,0 \times 10$ & Ausência & $<1,0 \times 10$ \\
\hline $\mathrm{B}$ & $3^{\mathrm{a}}$ & $<1,0 \times 10$ & Ausência & $<1,0 \times 10$ \\
\hline $\mathrm{C}$ & $1^{\mathrm{a}}$ & $4,9 \times 10^{3}$ & Ausência & $<1,0 \times 10$ \\
\hline $\mathrm{C}$ & $2^{a}$ & $<1,0 \times 10$ & Ausência & $<1,0 \times 10$ \\
\hline $\mathrm{C}$ & $3^{\mathrm{a}}$ & $<1,0 \times 10$ & Ausência & $<1,0 \times 10$ \\
\hline $\mathrm{D}$ & $1^{\mathrm{a}}$ & $3,4 \times 10^{3}$ & Ausência & $<1,0 \times 10$ \\
\hline $\mathrm{D}$ & $2^{\mathrm{a}}$ & $<1,0 \times 10$ & Ausência & $<1,0 \times 10$ \\
\hline $\mathrm{D}$ & $3^{\mathrm{a}}$ & $<1,0 \times 10$ & Ausência & $<1,0 \times 10$ \\
\hline $\mathrm{E}$ & $1^{\mathrm{a}}$ & $<1,0 \times 10$ & Ausência & $<1,0 \times 10$ \\
\hline $\mathrm{E}$ & $2^{\mathrm{a}}$ & $<1,0 \times 10$ & Ausência & $<1,0 \times 10$ \\
\hline $\mathrm{E}$ & $3^{a}$ & $<1,0 \times 10$ & Ausência & $<1,0 \times 10$ \\
\hline
\end{tabular}

\section{CONCLUSÃO}

Das cinco marcas de salame Tipo Italiano avaliadas provenientes de estabelecimentos comerciais de Francisco Beltrão, 100\% apresentaram-se em conformidade com a legislação nos parâmetros físico-químicos de proteína, carboidrato e lipídio e nos parâmetros microbiológicos de Salmonella sp. e Staphylococcos aureus.

Entretanto, para as análises físico-químicas de umidade, 60\% das marcas analisadas apresentaram resultados acima do estabelecido pela legislação. Apenas a marca $\mathrm{C}$ apresentou, em uma das amostras adquiridas, valores de atividade de água acima do permitido. Porém um dado preocupante diz respeito a $40 \%$ das marcas, as quais apresentaram contaminação por coliformes a $45^{\circ} \mathrm{C}$, colocando em dúvida a qualidade higiênico-sanitária durante o processamento destes salames.

Os resultados obtidos neste trabalho demonstram que as empresas devem melhorar seus controles de processo na fabricação de Salames Tipo Italiano, visando atendimento a legislação vigente, bem como, garantir a produção de alimentos inócuos, que não causem danos a saúde do consumidor.

\section{REFERENCIAS}




\section{9 a 22 de outubro de 2014 \\ Florianópolis/SC}

ANDREOLI, P. A.. Perfil bacteriológico e determinação da atividade de água de salame Tipo Italiano em três formas de comercialização no município de Niterói - RJ. Niterói: UFP, 2009.

BRASIL. Instrução Normativa n. 20, de 21 de julho de 1999. Regulamento técnico de identidade e qualidade de salame. Ministério da Agricultura e do Abastecimento. Brasília, 1999. Disponível em: <http://www.agricultura.gov.br/legislacao>. Acesso em 15 fev 2012.

BRASIL. Instrução Normativa n. 22, de 31 de julho de 2000. Regulamento técnico de identidade e qualidade de salame. Ministério da Agricultura e do Abastecimento. Brasília, 2000. Disponível em: <http://www.agricultura.gov.br/legislacao>. Acesso em 18 fev 2012.

BRASIL. Ministério da Saúde. Agência Nacional de Vigilância Sanitária - ANVISA, Resolução $\mathrm{n}^{\mathrm{o}} 12$ de 2 de janeiro de 2001. Regulamento Técnico sobre os padrões microbiológicos para alimentos. Brasília, 2001. Disponível em: <http://www.anvisa.gov.br/legis/resol/12_01rdc.htm>. Acesso em 20 mar 2014.

BRASIL. Instrução Normativa n. 62, de 26 de agosto de 2003. Ministério da Agricultura e do Abastecimento. Brasília, 2003. Disponível em: < http://www.agricultura.gov.br/legislacao $>$. Acesso em 19 fev 2012.

CACCIOPPOLI, J.; CUSTÓDIO, F.B.; VIEIRA, S.M.; COELHO, J.V.; GLÓRIA, M.B.A. Aminas bioativas e características físico-químicas de salames tipo italiano. Arquivo Brasileiro de Med. Vet.de Zootec v.58, n.4, p.648-657, 2006.

CAVALHEIRO, C. V. Características físico-químicas de embutido curado fermentado com adição de carne de avestruz associada à de suíno. Ciência Rural v.40, n.2, p.447-452, 2010.

FORSYTHE, S. J. Microbiologia da Segurança Alimentar. Porto Alegre: Artmed, 2002.

GARCIA, F. T.; GAGLEAZZI, U. A.; SOBRAL, P. J. A. Variação das propriedades físicas e químicas do salame tipo italiano durante a secagem e fermentação. Brazilian Journal of Food Technology v.3, p.151-158, 2000.

INSTITUTO ADOLFO LUTZ (IAL). Métodos físico-químicos para análise de alimentos. São Paulo: Adolfo Lutz, 2008. 506 p. $1^{\text {a }}$ Ed. Dig. Disponível em: <www. ial.sp.gov.br>. Acesso em 12 fev 2012.

KUCHENBECKER, B. S. Capacidade enterotoxigênica e perfil de resistência de Staphylococcus aureus isolados de produtos de origem animal inspecionados no Brasil. Porto Alegre: UFRGS, 2009.

MACIEL, J. F.; TEIXEIRA, M.A.; MORAES, C.A.; GOMIDE, L.A.M.Antibacterial activity of lactic cultures isolated of Italian salami. Brazilian Journal of Microbiology. São Paulo, v. 34, p. 121-122, 2003.

PARDI, M. C.; SANTOS, F.I.; SOUZA, E.R.; PARDI, H.S. Ciência, Higiene e Tecnologia da Carne. 2. ed. Goiânia: UFG, 2001.

SENTER, L.; ROSSI, E. M.; SARDIGLIA, C. U. A Avaliação da qualidade microbiológica de salames artesanais e implantação de boas práticas de fabricação em uma mini-indústria. Higiene Alimentar v.24, n.186/187, p.126-131, 2010.

STATSOFT, Inc. (2004). STATISTICA (data analysis software system), version 7.

STOLBERG, J.; VIOTT, A.; PELISSER, M. R. Qualidade microbiológica e físico-química de salames tipo coloniais da região do Alto Uruguai catarinense. Higiene Alimentar v.20, n.138, p.78-82, 2006. 
TERRA, A. B. M.; FRIES, L. L. M.; TERRA, N. N. Particularidades na fabricação de Salame. São Paulo: Varela, 2004.

TERRA, N. N. Apontamentos da tecnologia de carnes. São Leopoldo: Unisinos, 2005.

ZOCCHE, F.; BARCELLOS, V. C.; BERSOT, L. S. Micro-organismos indicadores e salmonella sp. em salames produzidos e comercializados na região oeste do Paraná. Revista Brasileira de Tecnologia Agroindustrial v.5, n.1, p.336-345, 2011. 